\title{
Diagnosis and Spontaneous Resolution of an Epidural Hematoma in a Patient Presenting after Cervical Epidural Steroid Injection
}

\author{
Julie Petro, MD, Abbas Asgerally, MD, Thomas Simopoulos, MD, Ivan Urits, MD, and \\ Musa Aner, MD
}

While not a cure for the underlying spinal pathology, cervical epidural steroid injections (CESI) are an important minimally invasive treatment for neck pain with radiculopathy. Although CESIs are considered safe, cervical epidural hematoma (CEH) is a major complication and has previously been reported. Patients, who develop CEH, present with acute neck pain and upper extremity radiculopathy. A prolonged time to treatment may lead to worsened neurological outcome. Diagnostic magnetic resonance imaging and surgical decompression is the mainstay of treatment. This report presents a patient with a history of chronic neck pain and repeat cervical injections, who presented with increased neck pain and upper extremity weakness after undergoing a CESI. Initial radiographic findings were complicated and inconclusive of a definitive epidural hematoma. With conservative management, the patient showed signs of clinical improvement and ultimately had spontaneous resolution of his $\mathrm{CEH}$. Though CEH are frequently rapidly progressing and most often surgically decompressed, some acutely presenting cases may be approached conservatively. Though MRI is an important diagnostic tool for $\mathrm{CEH}$, interpretation of radiographic findings, following a recent CESI, may be challenging due to distortion of the epidural space anatomy. Patients with a history of multiple cervical epidural injections may have an increased risk for the development of $\mathrm{CEH}$.

Key words: Cervical epidural steroid injection, cervical epidural hematoma, spontaneous resolution, conservative management, magnetic resonance imaging, complication
Neck pain is a leading cause of disability in adults. It is estimated to affect $37 \%$ of the entire adult population in a given year and approaches a $50 \%$ lifetime prevalence rate (1). Risk factors for developing neck pain include female gender, depression, smoking, middle age, and obesity (2). Duration of symptoms is the best predictor of outcome and when managed conservatively, longer duration of neck pain is associated with worsened prognosis $(3,4)$. Cervical radiculopathy is an important cause of neck pain and

From : Harvard Medical School, Beth Israel Deaconess Medical Center, Anesthesiology, Critical Care, and Pain Medicine, Boston, MA

Author for correspondence: Ivan Urits, MD

Address: Harvard Medical School, Beth Israel Deaconess Medical Center, Anesthesiology, Critical Care, and Pain Medicine, 330 Brookline Ave, Boston, MA 02215

E-mail: Iurits@bidmc.harvard.edu is estimated to affect 83 per 100,000 annually (5). The pathophysiology of cervical radiculopathy stems from mechanical compression of the cervical nerve root (6). Most commonly, this is caused by spondylosis due to chronic degenerative disk changes: loss of disc height, formation of osteophytes, facet joint hypertrophy, and foraminal narrowing (7). Ultimately, impingement of the exiting cervical nerve root causes focal ischemia and associated inflammatory biochemical changes, resulting in neuropathic symptoms and pain $(8,9)$.

While not a cure for the underlying spinal pathology, cervical epidural steroid injections (CESI) are an important nonsurgical treatment for neck pain with associated upper extremity radiculopathy. It is a commonly performed procedure in managing radicular discomfort and when successful, CESI can provide relief of pain and restoration of function to the affected 
extremity (10). Current literature supports the use of CESI in the treatment of cervical disc herniation and spondolytic foraminal stenosis (11). Though the therapeutic mechanism remains controversial, it is believed that corticosteroids deposited in close approximation to the affected nerve roots decreases the synthesis and release of pro-inflammatory mediators. Moreover, the addition of local anesthetic to the injectate blocks nociceptive input and may interrupt self-sustaining nociceptive transmission (12-14).

Although CESIs are considered safe, various adverse events have been reported. Overall, complication rates have been reported in the range of $0 \%$ to $16.8 \%$ (15). Common symptoms include axial neck pain and headache, secondary to soft tissue trauma and large volume injection. In this case report, we present the clinical course of a single patient who presented with acute neck pain and associated neurological deficits secondary to an epidural hematoma, after having undergone CESI for chronic neck pain with radiculopathy.

\section{CASE REPORT}

$\mathrm{JB}$ is a 65-year-old male with history significant for diabetes, bipolar disorder, schizoid personality disorder, anxiety, chronic back and neck pain with radiculopathy, secondary to multilevel cervical spondylosis and associated foraminal stenosis. $\mathrm{He}$ had been taking prophylactic aspirin $81 \mathrm{mg}$ daily; otherwise, he was not on any anticoagulation or nonsteroidal anti-inflammatory therapy. On October 25th, 2017 JB presented for his eighth C7-T1 ESI. Over the past 2 years, he had been undergoing repeat CESIs for neck pain and bilateral radiculopathy, right greater than left, and reported significant benefit with pain and symptom relief after each. Though his interlaminar CESI was uncomplicated, after obtaining loss of resistance for identification of the epidural space, spread of contrast dye was restricted to the dorsal epidural space (Fig. 1). Immediately following the procedure, there was no evidence of ecchymosis or bleeding. On October 26th, $2017 \mathrm{JB}$ complained of increased neck pain and presented to the emergency department (ED) for evaluation. There, he was found to have a $2 \mathrm{~cm}$ ecchymosis at the site of injection without erythema or induration. He had no fever or leukocytosis. His motor exam demonstrated $4 / 5$ strength for right handgrip, triceps extension, wrist flexion and extension, deltoid abduction, and $5 / 5$ strength on the left throughout. Magnetic resonance imaging (MRI) was obtained on October 26th 2017 revealing C6-7 and T1-2 epidural fluid collections (Fig. 2 and 3 ). There were no signal abnormalities; however, the cord was displaced at these spinal levels. Signal intensity of the epidural fluid collection was not fully consistent with either residual injectate or blood. Because of concern for a possible epidural hematoma, he was admitted to the hospital for observation; serial neurologic exams and MRI's were obtained. On October 29th, 2017 his pain and strength began to improve and a repeat MRI was obtained which revealed a persistent fluid collection, now radiographically consistent with hematoma. Given an improvement in symptoms and stable imaging, he was soon discharged to home with instructions to return to the ED should his condition deteriorate. An MRI at 2 months demonstrated resolution of the hematoma. He reported near complete improvement of his neck and upper extremity pain. On physical exam, his neurological examination was consistent with baseline recovery to $5 / 5$ strength in both extremities.

\section{DISCUSSION}

Despite an uneventful repeat CESI, our patient presented with symptoms of increased pain and upper extremity motor weakness. Cervical and radicular pain is an expected minor complication of CESI and can mask the initial presentation of an epidural hematoma. The patient's minor associated upper extremity weakness and profound pain were particularly concerning for the development of an epidural hematoma, prompting further investigation with imaging. Interestingly, the MRI Day 1 was not entirely consistent with acute hematoma; signal intensities on T2 images suggested the presence of either CSF or injectate fluid in the epidural space, while the visualized isointense signal intensities on T1 were suggestive of a hyper-acute hematoma. The injectate may be suspected as having interfered with the usual MRI signals. Given the lack of spinal cord signal abnormality and the patient's clinical stability, nonoperative management was elected. Follow-up $\mathrm{MRI}$, on post CESI day 4, revealed signal intensities which followed a pattern of evolution that was confirmatory for epidural hematoma rather than injectate 


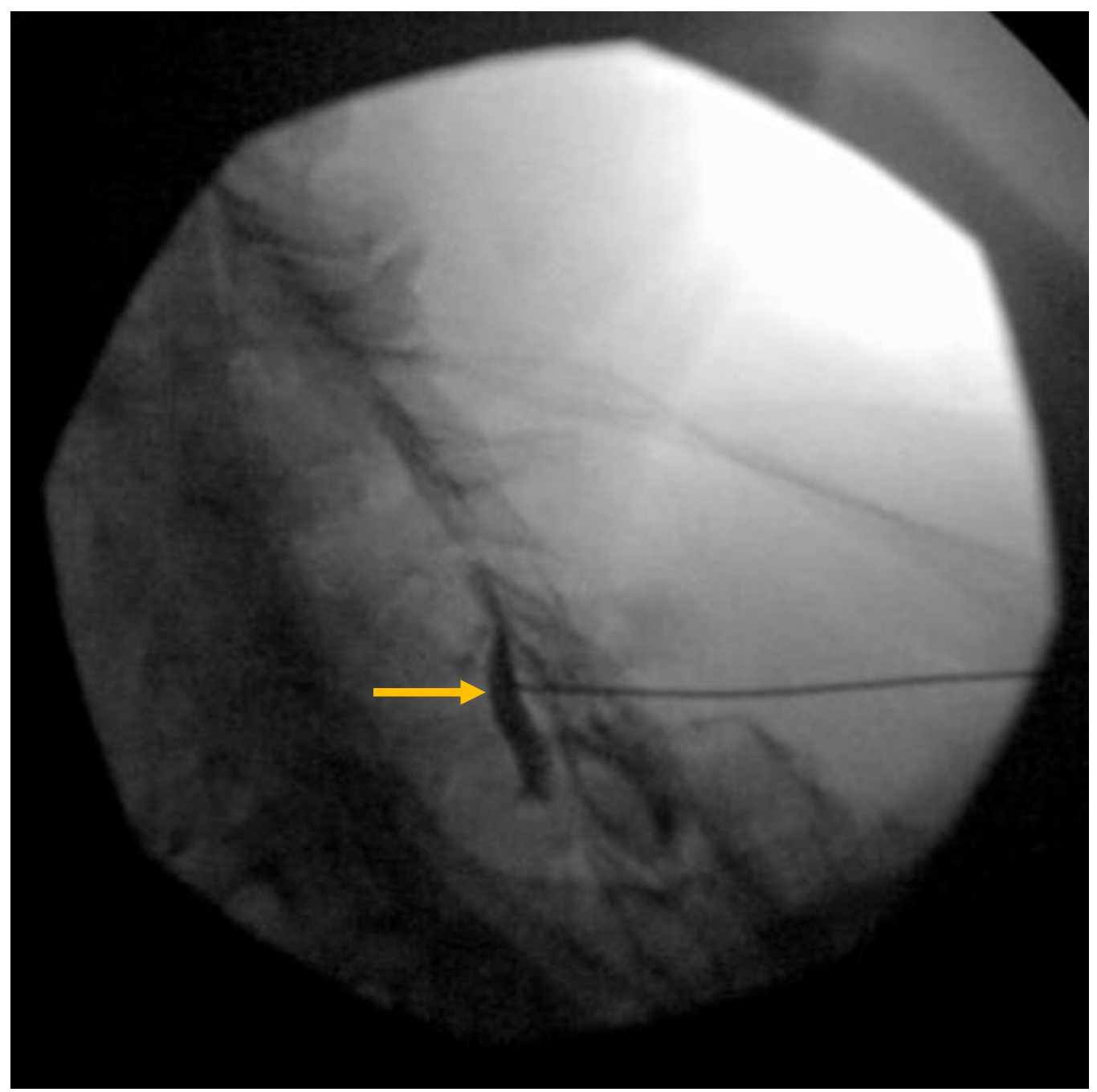

Fig. 1. Left contralateral oblique (CLO) view of contrast dye spread after cervical epidural steroid injection (CESI).

material. Moreover, in addition to the characteristic MRI findings, persistent leftward deviation of the spinal cord was consistent with the formation of an acute epidural hematoma (16). At this time, however, the patient had improved clinically, and reported decreased neck pain as well as decreased weakness in his upper extremities. Ultimately, a final follow up MRI, obtained at 2 months post CESI, revealed complete resolution of the hematoma. In this case, it was unclear if the initial MRI demonstrated residual injectate or a developing hematoma, delaying the establishment of a firm diagnosis. Though lumbar epidural injections have been shown to have no effect on MRI findings, the effect of CESIs has not yet been evaluated (17-19).

Cervical epidural hematomas $(\mathrm{CEH})$ are frequently rapidly progressing and lead to acute worsening of neurological deficits. Increased time to treatment is associated with worsened neurological prognosis (20-23). CEH initially presents with sharp neck pain radiating to the shoulder and arm. Clinical recognition of spinal bleeding following a CESI is difficult, as the symptoms of pain are often nonspecific and moreover masked by underlying pathology and analgesic effects of neuraxial blockade. Early diagnosis of a 

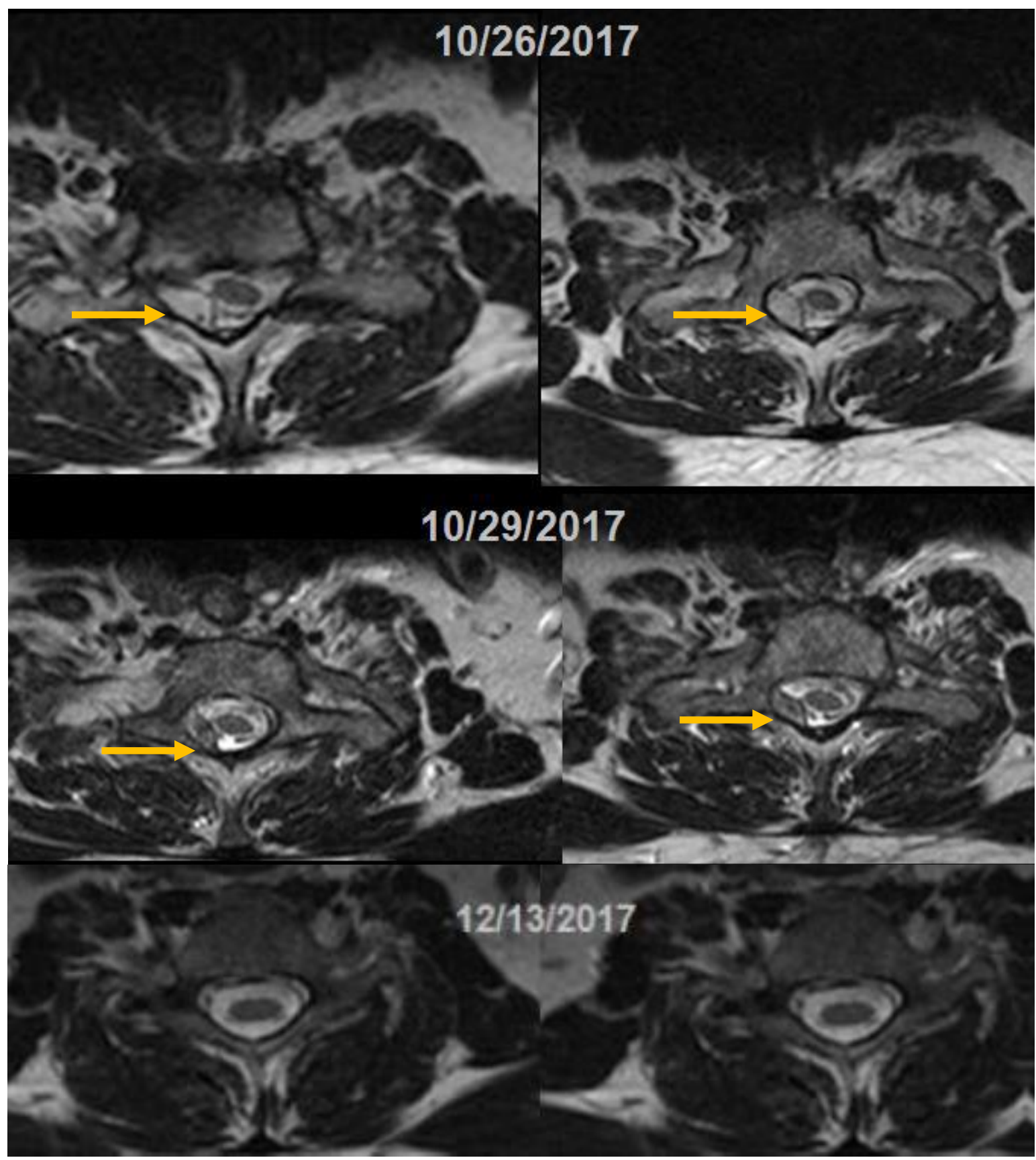

Fig. 2. Axial cervical magnetic resonance imaging (MRI). 10/26: Right C6-7 through T1-2, 1.5 x 0.7 x $4.0 \mathrm{~cm}, \mathrm{~T} 2$ hyper-intense with signal intensity similar to CSF, epidural fluid collection causing leftward deviation of the cord and mild deformation, with severe stenosis of the right neural foramina at C7-T1 and T1-T2. 10/29: Slight decrease in size of the right epidural collection, producing similar degree of mild spinal canal narrowing and associated severe neural foraminal narrowing. The collection is T2 hypo-intense to the CSF and spinal cord suggesting early blood products. 12/13: Interval resolution of right posterolateral epidural collection. 

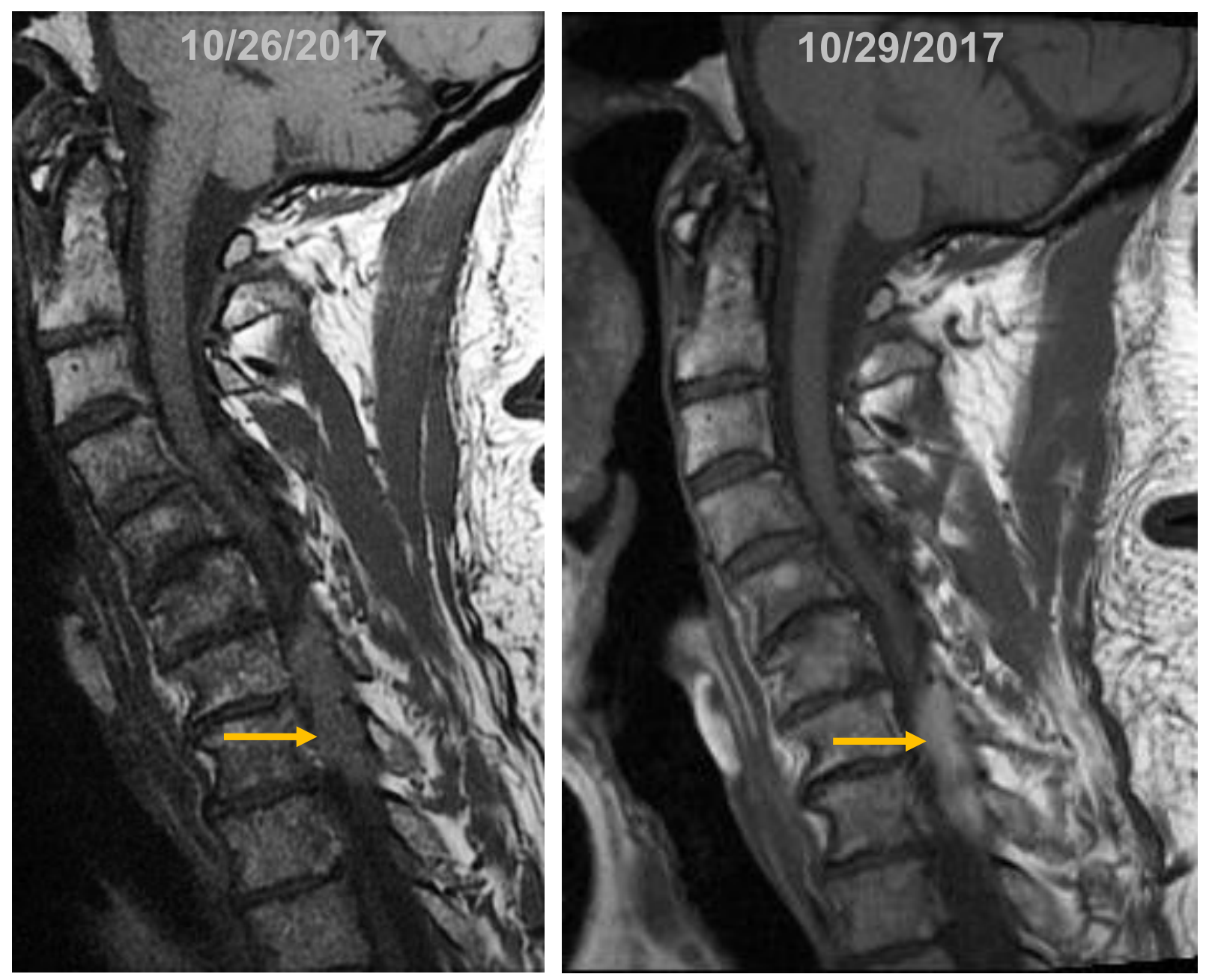

Fig. 3. Sagittal cervical magnetic resonance imaging (MRI). 10/26: T1 images show a collection which is isointense to slightly hyperintense to the spinal cord and cerebellum. 10/29: The collection is now hyperintense to the spinal cord and cerebellum.

rapidly evolving spinal hematoma and emergent surgical decompression is the mainstay of treatment and necessary in order to promote neurological recovery $(24,25)$. Despite this, patients demonstrating a significant improvement of symptoms over short periods of time may have spontaneous resolution of epidural hematoma when managed conservatively (26). Given that epidural hematomas frequently present with acute onset and rapidly worsening symptoms, reports of nonsurgically managed epidural hematomas after CESI are scarce.

Epidural hematoma is a major complication of ESI and has previously been reported (27-29). Associated patient risk factors for developing an epidural hematoma include anticoagulation and technically difficult placement (15,30-32). The overall incidence however is low. In a prospective 8 year single institution study of 1182 CESIs, a total of $2 \mathrm{CEH}$ were identified and subsequently decompressed surgically (33). Similarly, over the course of 16 years, only 2 cases were identified, in a retrospective study (27) of 23,552 patients, at a single facility. Our patient was not on anticoagulation or NSAID therapy. He was on maintenance low dose aspirin; though this is not considered a significant risk factor for spinal hematoma, 
concomitant aspirin use has been reported in cases of CEH $(34,35)$. Placement of his CESI was uneventful; however, unique to our patient was a history of multiple repeat CESIs, which may be a contributing risk factor in the development of a CEH. A similar observation was made once prior by Williams et al (23), who reported $\mathrm{CEH}$ in a patient following repeat CESIs for chronic pain. Underlying spinal pathology, such as spinal stenosis, herniated intervertebral disc, and tissue hypertrophy, as well as prior manipulation of the epidural space, can cause tissue fibrosis and scarring (36). All of these risk factors were present in this patient and may have led to an increased risk of epidural bleeding following CESI. Multiple repeat CESIs may be a risk factor for the development of $\mathrm{CEH}$ and practitioners should have a heightened suspicion of epidural hemorrhage in patients with this history. A larger retrospective multi-center study is needed to assess the risk of $\mathrm{CEH}$ developing in patients with a history of multiple CESIs.

\section{CONCLUSION}

CEH after a CESI is a rare, though serious, complication. In this case study, we report a developing $\mathrm{CEH}$ after a repeat CESI. The initial radiographic findings were not entirely consistent with hematomous fluid and diagnosis may have been complicated by residual injectate from the patient's recent CESI. Though symptoms of CEH are frequently dramatic in onset, requiring urgent surgical decompression, we report a spontaneous resolution of $\mathrm{CEH}$ with watchful waiting. Our patient's medical history was significant for multiple cervical injections which may constitute a risk factor for the development of $\mathrm{CEH}$.

\section{REFERENCES}

1. Fejer R, Kyvik KO, Hartvigsen J. The prevalence of neck pain in the world population: A systematic critical review of the literature. Eur Spine ] 2006; 15:834-848.

2. Strine TW, Hootman JM. US national prevalence and correlates of low back and neck pain among adults. Arthritis Care Res 2007; 57:656-665.

3. Peterson C, Bolton J, Humphreys BK. Predictors of outcome in neck pain patients undergoing chiropractic care: comparison of acute and chronic patients. Chiropr Man Therap 2012; 20:1.

4. Peterson CK, Bolton J, Humphreys BK. Predictors of improvement in patients with acute and chronic low back pain undergoing chiropractic treatment. J Manipulative Physiol Ther 2012; 35:525-533.

5. Radhakrishnan K, Litchy WJ, O 'Fallon WM, Kurland LT. Epidemiology of cervical radiculopathy $A$ population-based study from Rochester, Minnesota, 1976 through 1990. Brain 1994; 117:325-335.

6. Iyer S, Kim HJ. Cervical radiculopathy. Curr Rev Musculoskelet Med 2016; 9:272-80.

7. Rhee JM, Yoon T, Riew KD. Cervical radiculopathy. J Am Acad Orthop Surg 2007; 15:486-494.

8. Abbed KM, Coumans J-VCE. Cervical radiculopathy. Neurosurgery 2007; 60:S1-28-S1-34.

9. Kang JD, Stefanovic-Racic M, McIntyre LA, Georgescu HI, Evans $\mathrm{CH}$. Toward a biochemical understanding of human intervertebral disc degeneration and herniation. Contributions of nitric oxide, interleukins, prostaglandin E2, and matrix metalloproteinases. Spine (Phila Pa 1976) 1997; 22:1065-73.

10. Manchikanti L, Helm Ii S, Pampati V, Racz GB. Percutaneous

adhesiolysis procedures in the medicare population: Analysis of utilization and growth patterns from 2000 to 2011. Pain Physician 2014; 17:E129-E139.

11. Diwan S, Manchikanti L, Benyamin RM, Bryce DA, Geffert S, Hameed H, Sharma ML, Abdi S, Falco FJ. Effectiveness of cervical epidural injections in the management of chronic neck and upper extremity pain. Pain Physician 15:E405-434.

12. Abdi S, Datta S, Trescot AM, et al. \{list all authors\} Epidural steroids in the management of chronic spinal pain: A systematic review. Pain Physician 2007; 10:185-212.

13. Rabinovitch DL, Peliowski A, Furlan AD. Influence of lumbar epidural injection volume on pain relief for radicular leg pain and/or low back pain. Spine ] 2009; 9:509-517.

14. Hayashi N, Weinstein JN, Meller ST, Lee HM, Spratt KF, Gebhart GF. The effect of epidural injection of betamethasone or bupivacaine in a rat model of lumbar radiculopathy. Spine ( $\mathrm{Ph}$ ila Pa 1976) 1998; 23:877-85.

15. Abbasi A, Malhotra G, Malanga G, Elovic EP, Kahn S. Complications of interlaminar cervical epidural steroid injections: A review of the literature. Spine (Phila Pa 1976) 2007; 32:21442151.

16. Sklar EM, Post JM, Falcone S. MRI of acute spinal epidural hematomas. J Comput Assist Tomogr 1999; 23:238-243.

17. Kim MS, Jeong TY, Cheong YS, Kim MS, Jeong TY, Cheong YS, Jeon YW, Lim SY, Kang SS, Kim IN, Chang TB, Seong HH, Hwang BM. Effect of epidural corticosteroid injection on magnetic resonance imaging findings. Korean J Pain 2017; 30:281286.

18. Davidson EM, Sklar E, Bhatia R, Davidson EM, Sklar E, Bhatia R, Garcia L, Arheart KL, Ginosar Y, Birnbach DJ. Magnetic res- 
Conservative Management of a CEH after Steroid Injection

onance imaging findings after uneventful continuous infusion neuraxial analgesia: A prospective study to determine whether epidural infusion produces pathologic magnetic resonance imaging findings. Anesth Analg 2010; 110:233-237.

19. Davidson EM, Sklar EM, Ginosar Y, Davidson EM, Sklar EM, Ginosar Y, Abdi S, Bhatia RG, Garcia L, Hulen RB, Arheart KL, Birnbach DJ. Evaluation of magnetic resonance imaging following neuraxial steroid administration: Does epidural injection produce pathologic findings? Reg Anesth Pain Med 2008; 33:326-331.

20. Matsumura A, Namikawa T, Hashimoto R, Matsumura A, Namikawa T, Hashimoto R, Okamoto T, Yanagida I, Hoshi M, Noguchi K, Takami M. Clinical management for spontaneous spinal epidural hematoma: diagnosis and treatment. Spine J 2008; 8:534-537.

21. Bakker NA, Veeger NJGM, Vergeer RA, Groen RJM. Prognosis after spinal cord and cauda compression in spontaneous spinal epidural hematomas. Neurology 2015; 84:1894-903.

22. Zhao W, Shu L-F, Cai S, Zhang F. Acute cervical and thoracic ventral side spontaneous spinal epidural hematoma causing high paraplegia: A case report. Anesthesiol pain Med 2017; 7:e14041.

23. Williams KN, Jackowski A, Evans PJD. Epidural haematoma requiring surgical decompression following repeated cervical epidural steroid injections for chronic pain. Pain 1990; 42:197199.

24. Chiapparini L, Sghirlanzoni A, Pareyson D, Savoiardo M. Imaging and outcome in severe complications of lumbar epidural anaesthesia: Report of 16 cases. Neuroradiology 2000; 42:564-71.

25. Lawton MT, Porter RW, Heiserman JE, Jacobowitz R, Sonntag VKH, Dickman CA. Surgical management of spinal epidural hematoma: relationship between surgical timing and neurological outcome. J Neurosurg 1995; 83:1-7.

26. Zhang S, Geng F, Wang J, Zhang Z, Du C. Rapid recovery of spontaneous spinal epidural hematoma without surgical treatment: Case report and literature review. World Neurosurg 2018; 115:216-219.
27. Manchikanti L, Malla Y, Benyamin RM, Hirsch JA. Prevalence of epidural hematoma following cervical epidural injections in interventional pain management settings: Literature review with two case reports. Interv Pain Manag Reports 2017; 1:1117.

28. Swicegood JR, Manchikanti L, Benyamin RM, Hirsch JA. Two Cases of acute epidural hematoma formation after cervical interlaminar epidural steroid injections. Interv Pain Manag Reports 2017; 1:27-32.

29. Swicegood JR, Manchikanti L, Benyamin RM, Hirsch JA. A report of acute thoracic epidural hematoma after interlaminar epidural injection. Interv Pain Manag Reports 2017; 1:33-38.

30. Jenkie E, Benyamin R, Manchikanti L. Fish oil as a potential contributor to epidural hematoma following cervical epidural steroid injection: A case report and focused literature review. Interv Pain Manag Reports 2017; 1:19-26.

31. Benyamin RM, Vallejo R, Wang V, Kumar N, Cedeño DL, Tamrazi $A$. Acute epidural hematoma formation in cervical spine after interlaminar epidural steroid injection despite discontinuation of clopidogrel. Reg Anesth Pain Med 2016; 41:398-401.

32. Manchikanti L, Gruber TJ, Prabhakar H, Hirsch JA. Acute Epidural Hematoma Following a Cervical Epidural Injection in a Patient without Bleeding Risk. IPM Reports 2018;2;119-126.

33. Smith GA, Pace J, Strohl M, Kaul A, Hayek S, Miller JP. Rare neurosurgical complications of epidural injections: An 8-Yr single-institution experience. Oper Neurosurg 2017; 13:271278.

34. Honorio T. Benzon. Regional Anesthesia in the Anticoagulated Patient - NYSORA The New York School of Regional Anesthesia. [WWW document]. URL www.nysora.com/regional-anesthesia-in-anticoagulated-patient. Access date: 11/19/2018.

35. Sanders RA, Bendel MA, Moeschler SM, Mauck WD. Epidural hematoma following interlaminar epidural injection in patient taking aspirin. Reg Anesth Pain Med 2018; 43:1.

36. Lee JH, An JH, Lee SH. Comparison of the effectiveness of interlaminar and bilateral transforaminal epidural steroid injections in treatment of patients with lumbosacral disc herniation and spinal stenosis. Clin J Pain 2009; 25:206-210. 
